\title{
Carbon allocation among tree organs: A review of basic processes and representation in functional-structural tree models
}

\author{
André Lacointe* \\ UMR PIAF, INRA - Université Blaise Pascal, Site de Crouël, 234 Av. du Brézet, \\ 63039 Clermont-Ferrand Cedex 2, France
}

(Received 10 February 1999; accepted 21 July 1999)

\begin{abstract}
Carbon assimilates flow from "source" areas such as leaves to "sink" areas where they are taken up and used. The assimilate fluxes from sources to sinks are mainly dependent on the source-sink distances and on the respective abilities of the different sinks to take up and use the assimilates that are available to them. The widely accepted, basic mechanism of assimilate movement by mass-flow, although conceptually simple, has so far proved too complex for practical modeling purposes in whole tree systems. Four main modeling approaches can be found in current models: (i) models involving empirically determined allocation coefficients; (ii) models based on growth rules, including functional balance or "goal-seeking" principles; (iii) transport-resistance models; (iv) models based on relative sink strength, with two main sub-classes: "hierarchical" and "proportional" models. These different model classes can be conceptually closer to each other than is readily apparent. They are presented in relation to their generality and ability to account for complex architectures or responses to environmental changes. The feedback relationship of allocation to growth is pointed out.
\end{abstract}

assimilate / partitioning / source / sink / model

Résumé - La répartition du carbone entre organes chez les arbres : processus de base et représentation dans les modèles «structure-fonction ». Les assimilats carbonés circulent de zones «sources » telles les feuilles, vers des «puits » où ils sont prélevés et utilisés. Ces flux d'assimilats dépendent principalement des distances entre sources et puits ainsi que des capacités respectives des différents puits à prélever et utiliser les assimilats disponibles. Il est largement admis aujourd'hui que le mécanisme de base de la translocation est un flux de masse. Mais malgré sa simplicité conceptuelle, la simulation de ce processus implique des calculs trop complexes pour une modélisation pratique. On trouve actuellement quatre approches modélisatrices principales : (i) l'utilisation de coefficients d'allocation empiriques; (ii) la mise en œuvre de règles de croissance, notamment des équilibres fonctionnels et autres principes téléonomiques; (iii) l'analogie électrique avec des résistances; (iv) des règles de répartition basées sur les « forces » relatives des différents puits (modèles hiérarchiques et modèles proportionnels). Ces diverses classes de modèles sont parfois conceptuellement moins éloignées les unes des autres qu'il n’y paraît. Elles sont présentées en relation avec leur généralité et leur capacité à rendre compte d'une architecture complexe ou des influences de l'environnement. On souligne l'importance des rétroactions entre allocation et croissance.

assimilats / allocation / source / puits / modèle

* Correspondence and reprints

Tel. 04736243 67; Fax. 04736244 54; e-mail: lacointe@ clermont.inra.fr 


\section{INTRODUCTION}

Assimilate allocation is a key component in functional-structural tree models (FSTMs). In the short term, partitioning of the whole-plant carbon among the different sink organs and/or functions determines the relative growth rates of the various plant components, including structural as well as harvestable parts. However, assimilate allocation is involved in a number of feedback processes which make it even more central in the longer term (figure 1). As a significant example, young sink leaves, the growth of which is dependent on current assimilate allocation, will later become carbon sources, thus affecting the future carbon inputs. As another example, the growth of sinks is both the result of carbon allocation to them and a major determinant of the carbon allocation pattern (see below). A third example is the feedback effect of sink activity on the current photosynthetic activity [12].

These dynamic and feedback aspects of carbon allocation make it a very sensitive point regarding the longterm stability of FSTMs, such that significant progress that has been achieved recently in modelling other processes, such as photosynthesis [19], may prove use- less. Unfortunately, carbon partitioning often remains a weak point in current models, although its basic principles and mechanism are relatively simple and fairly well understood.

The first part of this paper provides a short overview of these basic features; then the different approaches that have been used in modelling $\mathrm{C}$ allocation are reviewed and discussed in relation to their domains of validity, flexibility, and ability to account for the effects of environmental factors. Although this review is dedicated to tree models, a few key papers or studies not specific to trees will be mentioned when appropriate, as the basic mechanisms and modelling approaches are similar in all kinds of plants.

\section{WITHIN-TREE ALLOCATION: BASIC PRINCIPLES AND MECHANISM}

In the last 50 years assimilate allocation in trees has given rise to hundreds of studies $[7,16,30]$. Beyond some specificities related to the diversity of experimental conditions, a few general features arise.

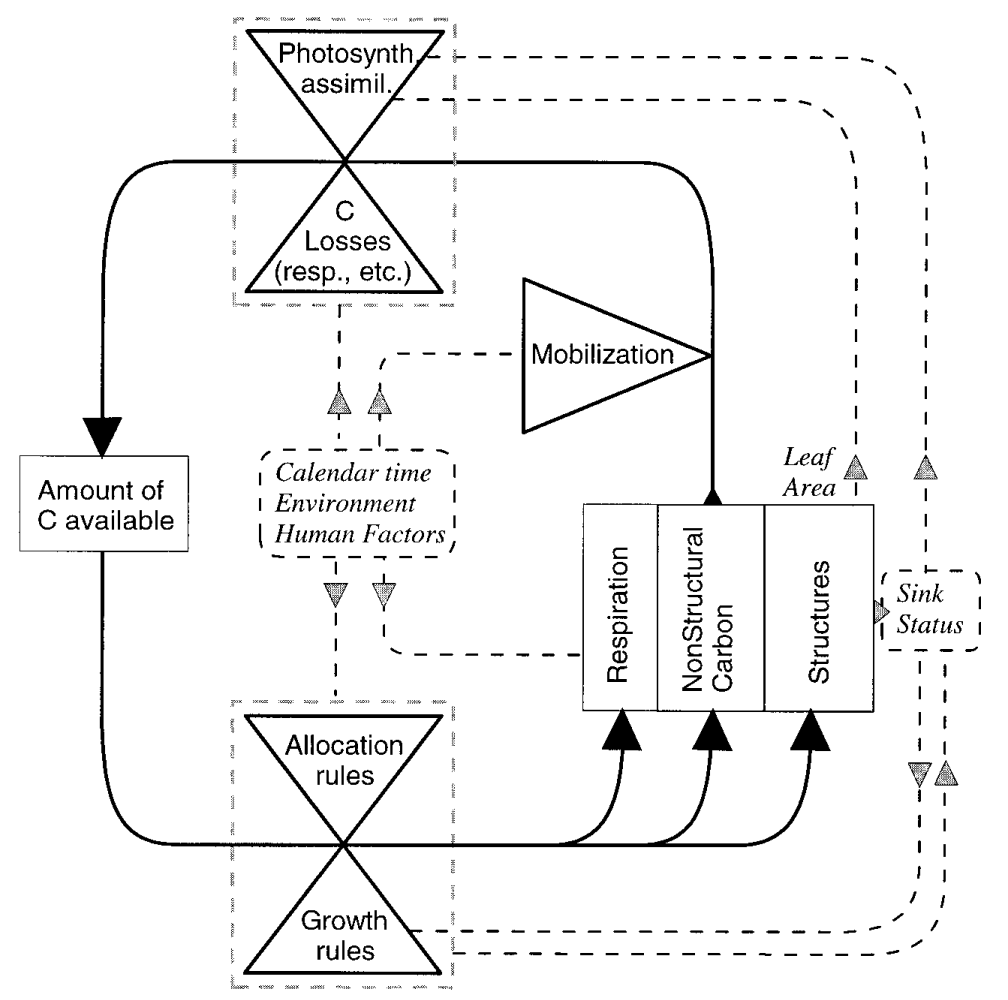

Figure 1. Simplified structure of a general functional-structural tree model. Carbon flows are symbolised by solid lines; dashed lines indicate some possible environmental or feedback effects. The allocation submodel tightly interacts with the growth submodel to yield the actual partitioning pattern (lower box), in some cases to such a degree that both submodels cannot be separated. Depending on the scope of each model, some elements of this general frame may be either missing or developed to a much higher extent. 


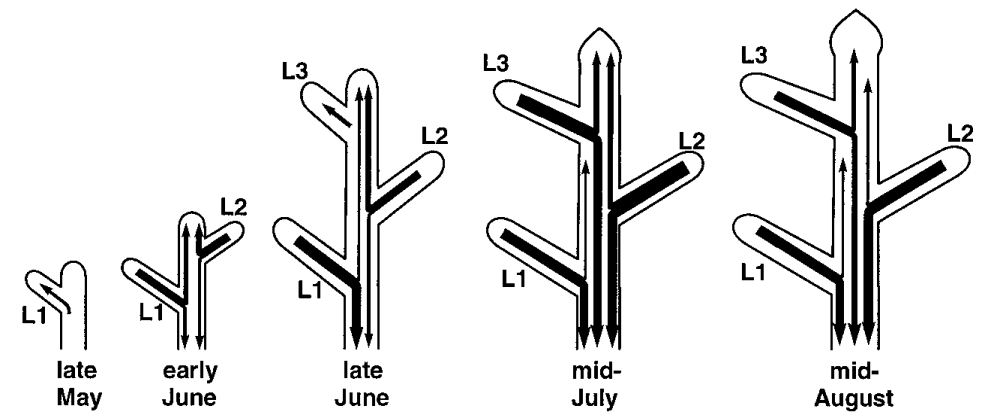

Figure 2. Changes in export directions of assimilates from the different leaves of Populus grandidentata. Leaves are numbered from basal (L1) to apical (L3). Arrow widths are roughly proportional to assimilate fluxes (redrawn after [17]).

\subsection{A dynamic allocation pattern}

The direction of assimilate movement from a source leaf is dependent on the location of that leaf within the plant, more specifically on the respective distances to the different sinks. In short, distal source leaf photosynthates are exported mainly to distal directions, i.e. towards the meristem and growing leaves and internodes, whereas photosynthates from proximal leaves are directed mainly away from the leaf canopy, i.e. towards the root system [16]. This is a dynamic system [17]: as the stem grows and the relative position of a given leaf becomes less distal, the fraction of assimilates from that leaf exported to the distal direction decreases (figure 2). Furthermore, this shift may be reversible in relation to changes in the relative aboveground vs. belowground sink activities, e.g. fruit growth [11]. Generally, changes in the source:sink ratio (e.g. by removing either some sources or sinks) induce changes in the relative amount of assimilates imported by the different sinks. These changes are generally not proportional to the preexisting fluxes [73].

\subsection{Impact of environmental factors}

The effects of minor nutrients or temperature on assimilate allocation are highly variable [7, 77] and will not be considered here. However, major factors such as water, major mineral nutrients or light availability affect the relative carbon allocation to the different plant parts, particularly the shoot:root ratio, in a way that can be described simply, at least in the long term, i.e. a week or more. A shortage in water, nitrogen or phosphorus or an elevated $\mathrm{CO}_{2}$ level generally results in a decreased shoot:root ratio, whereas low irradiance induces the opposite response [7, 33, 49, 77]. The interesting point is that in all cases, the plant part responsible for the uptake of the limiting resource (roots for water and nutrients, shoots for light) grows more relative to other organs than under unrestricted conditions, which results in an improved uptake of that limiting resource. This sensitivi- ty of the shoot:root ratio to external factors, leading to a balance in the uptake of the various resources, has been considered in models either as a basic modelling principle (see below, "functional balance") or as a consequence that should be derived from more basic, mechanistic processes as described by the Münch theory or transport-resistance models.

\subsection{Basic mechanism: The Münch theory}

The mechanism of assimilate transfer and allocation throughout the plant is now widely accepted to be massflow, as assumed by Münch [47] after a famous experiment (1930). The phloem sap mass flow within the sieve tubes is driven by a hydrostatic pressure gradient $(\Delta P)$ between source and sink. $\Delta P$ is itself linked to a difference, between both ends of the pathway, in xylemphloem osmotic potential gradient (figure 3). Since the xylem sap solute concentration is very low throughout the plant, this axial difference in xylem-phloem osmotic gradient is essentially due to an axial gradient in phloem osmoticum, which results from sustained phloem loading at the source end and unloading at the sink end. Assuming the sieve-tube to be a simple capillary pipe, the water mass-flow rate $J_{\mathrm{w}}$ is yielded by the PoiseuilleHagen law:

$$
J_{\mathrm{w}}=-\frac{\pi \cdot a^{4}}{8 \cdot \eta} \cdot \frac{\Delta P}{L}
$$

( $a$ : radius of capillary; $L$ : length of capillary).

However the sieve-tube is not a simple capillary pipe, as its lateral membranes are almost semipermeable and consecutive sieve elements are separated by sieve plates. Recently a few authors took these characteristics into account, which gave rise to more refined models $[3,15$, 56]. Although the TRANS model [3] has been used to investigate assimilate transfer within one stem segment, the formulations (and numerical calculations) of these theoretical models are too complex for practical 


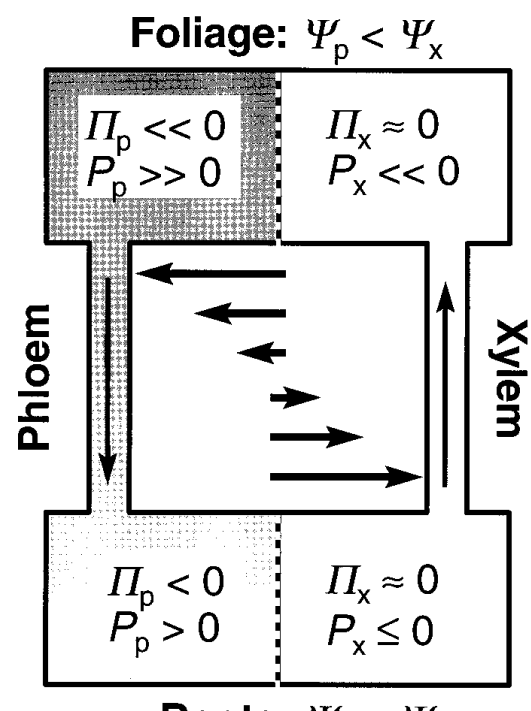

Roots: $\Psi_{\mathrm{p}}>\Psi_{\mathrm{x}}$

Figure 3. The Münch model of assimilate mass-flow transport. Assimilates are actively loaded into the phloem sieve tubes in sources (leaves) and unloaded in sinks (e.g. roots), generating an osmotic, resulting in a hydrostatic, pressure gradient which drives the mass flow within the sieve tubes. Arrows symbolise the water fluxes. $\Pi$, osmotic potential; $P$, hydrostatic pressure; $\Psi$, water potential: $\Psi=\Pi+P$. Indices $p$ and $x$ refer to phloem and xylem, respectively (redrawn after [14]).

inclusion as FSTM components. Nevertheless, they confirm that the steady-state water mass flow rate $J_{w}$, and the solute dry matter flow rate $J_{\mathrm{s}}$ as well, is actually proportional to the pressure gradient and inversely proportional to the pathway length $(L)$ :

$$
J_{\mathrm{s}}=(k / L) \Delta P \text { or } J_{\mathrm{s}}=\Delta P / R \text { where } R=L / k .
$$

This may be considered as the theoretical basis for a particular class of FSTMs: transport-resistance models, as reported below.

\section{MODELLING ASSIMILATE ALLOCATION}

Four main classes of models have been used to date: empirical models, growth rule-based models, transportresistance models and models based on source/sink relationships. In the following, the fraction of the total available carbon allocated by the model to a given sink \# $j$ is referred to as the allocation coefficient, $\lambda_{j}\left(\Sigma \lambda_{j}=1\right)$. Where the local source of assimilates can be traced, the double-indexed notation $\left(\lambda_{i j}\right)$ is used to denote the proportion of assimilates from source \# $i$ that is allocated to $\operatorname{sink} \# j$.

\subsection{Empirical carbon allocation models}

In empirical models, no general mechanism or rules are assumed to drive the allocation pattern. The allocation coefficients are measured experimentally. This can be done either directly, by labelling the $\mathrm{C}$ flowing from each source and tracing it to each sink $[51,78]$ or indirectly, from the growth rates of the different sinks [37, $44,50]$. In the latter case no distinction is possible among the various sources; only the partitioning of the total $\mathrm{C}$ available at the whole plant level can be assessed.

The labelling approach provided Rauscher et al. [51] with a very detailed, comprehensive matrix of allocation coefficients from each source leaf to each sink, which was included in their model ECOPHYS of one-year-old poplar cuttings. This approach is practically very efficient as photosynthetic assimilation can be immediately translated into growth rates of the different plant parts. The main shortcoming, on the other hand, is that the allocation coefficients are valid only for a limited range of conditions and should be measured again in each different situation, whether regarding the environment or plant material. However, an extension of ECOPHYS from the one-year-old cutting to older trees has been attempted by maintaining the within-twig allocation pattern and extrapolating export out of the twig from root allocation [28].

In order to take the seasonal variation of the partitioning pattern into account, several authors $[50,78]$ interpolated allocation coefficients that had been measured at different times in the year. Some flexibility with respect to environmental control could be introduced into this intrinsically rigid (though dynamic) system through a modulation of the root allocation coefficient $\left(\lambda_{\text {root }}\right)$ by soil water potential $\left(\psi_{\mathrm{s}}\right)$, and keeping the same proportionality among the remaining allocation coefficients [78]. Although the authors did not indicate the domain of validity for this modulation, it qualitatively accounted for the impact of water availability on the shoot:root ratio as reported above:

$$
\lambda_{\text {root }}=\lambda_{\mathrm{r} 0} \times\left(1+0.2\left(-\psi_{\mathrm{s}}\right)^{0.5}\right) .
$$

Another example of modulation by external factors can be found in work by Mäkelä and Hari [37], where the different allocation coefficients are set as functions of the light environment.

In spite of this possible modulation of allocation coefficients, empirical models cannot be valid over wide ranges of conditions. They have been used for forest trees, where they are appropriate to simulate under well defined conditions the growth of trees of simple [50, 51] or simplified $[44,78]$ development patterns, with a typical time step of ca. one day $[50,51,78]$. 


\subsection{Growth rule-based models}

Models in this class include a more or less thorough description of a priori growth patterns or relationships within the plant. $\mathrm{C}$ fluxes are considered more a consequence than a determinant of the growth pattern, so that in a few cases no carbon balance is computed at the tree level [29, 61]. Empirical allometry, architectural rules and functional (or goal-seeking) relationships are the three main kinds of growth rules used in these models.

\subsubsection{Empirical allometry}

These models include some empirical relationships between dimensional variables such as tree height, stem length, diameter, leaf area, weights or volumes... The relationships can be considered as describing some implicit and generally complex, though not clearly identified, internal constraints or balances. They are generally in the form of multiplicative power functions:

$$
Y=k X_{1}^{a}\left(\times X_{2}^{b} \ldots\right) .
$$

West's model [76] includes a number of such relationships, e.g. between leaf weight and supporting branch weight. Similar relationships can be found in works by Deleuze and Houllier [13] and Mäkelä and Sievänen [39]. For example, Deleuze and Houllier [13] included Pressler's rule, which states that the cross-section of the latest annual ring at any given height of the stem is proportional to the total leaf surface area (or dry matter) above that height. Inequalities can also be found in these models to keep the plant shape or size within a realistic range [76].

Empirical allometry models have a domain of application similar to empirical carbon allocation models in forestry, but with a wider time step: typically one year, which allows simulation on decades. In their basic form, they exhibit as little flexibility as empirical carbon allocation models do; however, in most cases they include (beside mere empirical allometry) some functional relationships, which can include an explicit modulation by environmental factors (see below, functional balance).

\subsubsection{Architectural rules}

Branching rules, including branching angles and/or topology, can be included in FSTMs to describe the architectural growth pattern of the tree crown. Different architectural models are specific to particular kinds of plants. The simulated architecture, and hence the corresponding rules, may be theoretical and/or very simple, e.g. for coniferous-like trees, as found in LIGNUM [48] or in Takenaka's model [61]. Alternatively, the rules can provide a very detailed description of tree architecture based on complex botanical characters as found in the AMAP series [52, 53].

Architectural rule-based models are mainly used in forestry. Although they can be stochastic, thus allowing some individual variability, they still have few degrees of freedom left. As a consequence, most of the partitioning pattern is determined a priori, e.g. in AMAPpara where the allocation submodel mostly drives the stem radial growth $[52,53]$. Thus, similar to empirical models, they are valid only on a limited range of conditions, namely that under which the architectural parameters are not altered. However, some flexibility can be introduced if the architectural parameters are set as functions of the environment. In the models of Kellomäki and Strandman [29] and Takenaka [61], shoot growth and/or abscission rates are dependent on local light conditions; in work by Sorrensen-Cothern et al. [58] they are dependent on both local and whole-tree carbon balance. When architectural rules include such environmental effects, they become, in essence, close to functional relationships, as seen in next section, although they address finer scales.

\subsubsection{Functional balance and teleonomic models}

When a particular allometric relationship between specific growth variables is recognised or suspected to have a clear functional or adaptive meaning, it becomes a functional relationship instead of a mere empirical one. When the relationship parameters differ in different conditions, which provides a powerful way to include environmental effects in the model, that may be understood as an adaptive response to environmental factors. More specifically, the teleonomic or "goal-seeking" approach envisions the plant's "strategy" as partitioning or "investing" its resources among the different organs and functions in an optimal way with respect to some "purpose" such as achieving the longest life span, the maximum seed production, or - most often - the highest growth rate possible in its particular environment.

As functional relationships generally address large organs or compartments, they are rather poor at accounting for complex or variable architectures (however, see "architectural rules" above). The most significant examples of functional balance are root:shoot functional activities, leaf support by sapwood ("pipe model"), and mechanical support.

\subsubsection{Functional balance of root/shoot activities}

According to the root:shoot functional balance principle, total nitrogen acquisition by the root system is proportional to total carbon assimilation by the aboveground parts. In other words, the shoot:root weight ratio $\left(W_{\mathrm{s}} / W_{\mathrm{r}}\right)$ 


$$
\sigma_{\mathrm{s}}=\frac{1}{W_{\mathrm{s}}} \cdot \frac{d C}{d t}
$$

$$
\sigma_{\mathrm{r}}=\frac{1}{W_{\mathrm{r}}} \cdot \frac{d N}{d t}
$$

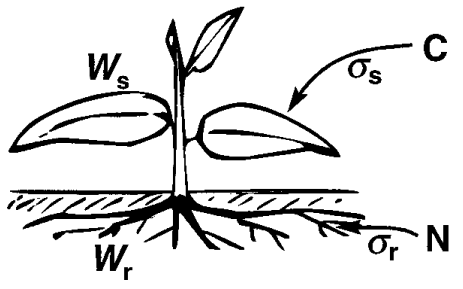

$$
\frac{W_{\mathrm{s}}}{W_{\mathrm{r}}}=\pi \cdot \frac{\sigma_{\mathrm{r}}}{\sigma_{\mathrm{s}}}
$$

Figure 4. Functional balance between shoot and root activities, $\sigma_{\mathrm{s}}$ and $\sigma_{\mathrm{r}}$, according to Davidson [10]. $W_{\mathrm{s}}$, $W_{\mathrm{r}}$ : dry matter weights of shoot (resp. root) actively involved in $\mathrm{C}$ (resp. $\mathrm{N}$ ) acquisition. is inversely proportional to the shoot:root ratio of specific activities $\left(\sigma_{\mathrm{s}} / \sigma_{\mathrm{r}}\right)$, i.e. the rates of $\mathrm{C}$ (resp. $\mathrm{N}$ ) acquisition per shoot (resp. root) unit weight (figure 4). This expresses the impact of $N$ availability on the shoot:root ratio (see above, "impact of external factors"):

$$
\frac{W_{\mathrm{s}}}{W_{\mathrm{r}}}=\pi \cdot \frac{\sigma_{\mathrm{r}}}{\sigma_{\mathrm{s}}} .
$$

This equation [10] has been included in many FSTMs $[13,34-36,39,40,48,70,71,72]$. It has been used as a way to model the effect of $N$ availability on the shoot:root ratio, by allowing the specific activities to change with soil conditions [39], although not only those but also the "constant" $\pi$ may actually change with $N$ availability [7].

In its basic formulation, the root:shoot functional relationship can be considered a teleonomic principle, which equation (4) expresses in an integrated form. Several authors, after Reynolds and Thornley [55], gave differential formulations of that principle, where the allocation coefficients are computed as solutions of an optimisation equation. More recently, Reynolds and Chen $[8,54]$ proposed a "coordination theory" where the allocation coefficients are driven by the imbalance between root and shoot activities. Although this does not require the plant to "anticipate" the environmental conditions as does the basic teleonomic principle, it is still assumed that the plant "knows" what it has to do. However, it has been shown $[38,68]$ that equation (5) can be derived without any teleonomic or other integrative assumption. It may actually be derived from the mechanistic bisubstrate transport-resistance formulation (see below), assuming exponential growth (which indeed is a very strong assumption for temperate trees).

\subsubsection{Leaf support by sapwood: The Pipe-Model}

In 1964, Shinozaki et al. [57] found an experimental relationship between the foliage weight $\left(W_{\mathrm{f}}\right)$ of a tree and the cross section of underlying sapwood $(A)$, which could be understood as a functional balance as the sapwood provides the foliage with water:

$$
W_{\mathrm{f}} / A=\eta
$$

where $\eta$ is a species-dependent proportionality constant.

This relationship has been used in a number of recent models, often associated with the root:shoot functional balance equation $[6,34-36,40,48,70,71,72]$ or with other allometric relationships [76].

The proportionality constant $\eta$ is often $[6,34-36,40]$ assigned different values at different height levels in the tree, e.g. one for the stem below the crown, one for the branches and one for the coarse roots (figure 5), which is more realistic [7] than a single value for the whole tree as in the original formulation. Berninger and Nikinmaa

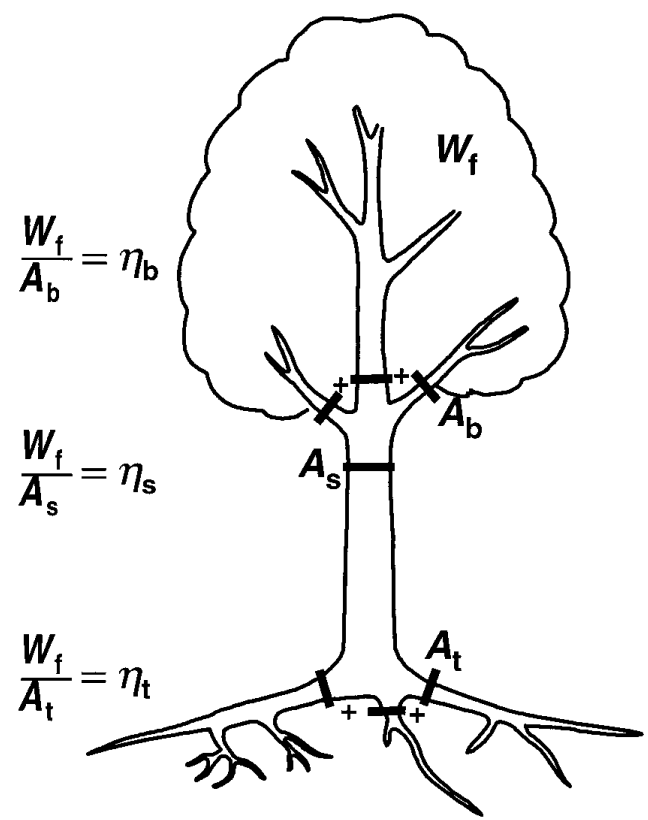

Figure 5. The pipe model, after Mäkelä $[34,36]$. At any given level $i$ in the tree $(i=b, s, t)$ the total sapwood area $A_{i}$ is proportional to the total foliage biomass $W_{\mathrm{f}}$. Indices $b, s, t$ refer to, resp.: primary branches at foliage base, crown base, and transport roots at stump (redrawn after [36]). 
[6] could simulate a climatic modulation of carbon allocation by assuming a further dependence of $\eta$ on the local mean potential evapotranspiration.

\subsubsection{Mechanical constraints}

Beside the hydraulic point of view as used in the pipe model, the stem also provides mechanical support to the foliage. Obviously, the stem or branch wood structure must support the foliage, and more generally the biomass above any height level, with regard to gravity or any mechanical loads such as wind or neighbouring trees. In this context, "support" can mean either "be strong enough to prevent failure" (strength design) or "be stiff enough to prevent excessive drooping or buckling" (maximal span design) [46]. It has been suggested that the stem taper profile is in many cases [7, 43] close to that just required for a safe and "harmonious" growth, indicating functional balance. Actually, depending on the type of load (self weight, wind...), the type of structure (main stem, branch) under concern, and the type of strategy considered (safety strength or span), the "optimal design" can vary $[41,42,46,76]$. Assuming very simplified shape and load conditions, McMahon and Kronauer [43] predicted tree stems and branches with a power law tapering:

$$
D=k L^{\beta}
$$

[D: diameter at distance $L$ from the point where $D=0$ ]

and found in a few isolated trees a $\beta$ value of ca. 1.5, which is a condition for elastic self-similarity (maximal span design) where all segments within the branch exhibit the same deflection profile under self weight [7, $21,43]$. However, different taper profiles have also been reported, including that expected for uniform stress along the stem under self-weight and negligible crown weight (strength design), with a $\beta$ value of 2.0 [7].

A differential expression of the 1.5 power law tapering (elastic similarity) was used by Ford et al. [21, 22] to partition assimilates between elongation and radial growth in coniferous branches so that branch posture in the vertical plane followed a particular deflection profile. To our knowledge, this is the only FSTM where a mechanical principle explicitly drives $\mathrm{C}$ allocation, although West [76] also mentioned this concept as the principle underlying some allometric relationships between stem and crown dimensions. However the mechanical basis of general allometric laws has been deeply challenged by more recent biomechanical studies [46], and more realistic but more complex models have been proposed, involving growth explicitly [23, 42]. As a consequence, a biomechanical module called AMAPmeca [53] was introduced in the AMAP series. It can use the current architecture as input to compute the distribution of mechanical stresses and strains due to self weight, simulate the effect of reaction wood as changes in local mechanical properties, and derive new orientations for the different stem or branch segments which can be used by the main AMAP engine in turn to compute architecture for the next time step. Assuming architectural rules (see above) depend on branch orientation and/or mechanical stress, $\mathrm{C}$ allocation can be indirectly affected in this way.

Functional relationships have been included in a number of forest FSTMs. They provide simple ways to set dimensional ratios between different plant parts. In essence they are much more flexible and responsive to external factors than mere allometric relations. However, their validity has been questioned by modelers and physiologists [7, 8, 21, 54, 69]. At least on a qualitative level, the shoot:root functional balance and the mechanical balance concepts have some experimental and theoretical foundations, although Davidson's rule may be considered as a consequence of more mechanistic principles rather than as a basic principle (see above). On the other hand, the "pipe model" as a $\mathrm{C}$ allocation principle has been questioned by several authors [7, 21], not only because of theoretical considerations regarding the relationship between sapwood area and leaf weight (and its actual variability), but also because of the variable relationship between hydraulic properties and carbon content (or cost) of wood structures, in relation to wood anatomy. Ford and Ford [21] chose mechanical balance rather than the pipe model as a foliage:wood partitioning principle for their model after discussing both hypotheses.

Why have mechanical concepts been included in so few FSTMs? The complexity of calculations may be part of the answer. However, more basic reasons are probably involved as well: (i) It is difficult to measure and model the intensity (and variability) of mechanical factors other than gravity (e.g. mechanical stimulation induced by wind or neighbour trees), all the more so as the relevant scales of space and time are still being debated [9, 60, 62]. This is is a major point to account for environmental variability. (ii) Whereas the mechanical behaviour of existing structures is fairly well understood and predictible provided mechanical parameters are known, knowledge about the active response of current elongation and radial growth (thigmomorphogenesis) to mechanical stress, including induction of reaction (or "flexure") wood, has still to be improved. Nevertheless, significant progress has been made in recent years $[7,23$, $41,42,53]$, so that more models including mechanical modules should be available in the future.

\subsection{Transport-resistance models}

Transport-resistance (TR) models describe assimilate movements as driven by concentration gradients across 
resistive pathways. As the mechanism by mass-flow actually results in a resistive-like formulation (Eq. 2), transport-resistance models can be considered the most mechanistic models available today. However, it should be pointed out that they explicitly simulate a diffusive rather than a mass-flow process. As a consequence, very short-term dynamic aspects are ignored by TR models; this is generally not a problem as time steps are one day or more. The original formulation by Thornley $[64,65]$ involved 2 solute substrates ( $\mathrm{C}$ and $\mathrm{N}$ ) which moved in opposite directions between shoot and root. Combined with a bi-substrate kinetic law for dry matter growth, this could account qualitatively for the effect of nitrogen on the shoot:root ratio as discussed above. Dewar [15] showed that this qualitative result still holds when taking into account the actual complexity of $N$ movements which occur through both xylem and phloem in opposite directions.

In spite of their conceptual interest, TR models have not been widely used in FSTMs. So far they have been applied only to models with very little, if any, architecture. Deleuze and Houllier [14] developed a single-substrate $(\mathrm{C})$ version to simulate stem radial growth ("reaction-diffusion" model). Thornley [67] proposed an extended, very detailed stand version of the bi-substrate model, which was included by Luan et al. [32] in the FORDYN model. The reason why TR models have remained essentially theoretical is mostly the difficulty in estimating the model parameters. Whereas resistances can be understood as the phloem pathways, the definition of potentials is not so clear, particularly at the sinkor source-pathway interfaces. After the theoretical work of Minchin et al. [45] who used the Michaelis-Menten formulation, progress in modelling the "sink strength" (see next section) should improve this crucial point.

\subsection{Source-sink relationships-based models}

This class includes models that are nearly as mechanistic as the TR models, however they have been much more widely used. Here, assimilate fluxes and allocation are assumed to depend on the respective ability of the different sinks to import available assimilates from the sources. In models, this ability, or "sink strength" [20], is

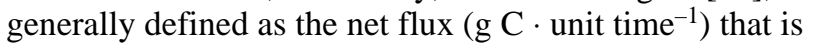
imported into a sink under particular, often "non-limiting" conditions; specific rules allow then to compute the actual fluxes imported under the current conditions. Theoretically the sink ability to import and use available assimilates should encompass both carbon deposition as new dry matter and carbon losses as respiratory $\mathrm{CO}_{2}$. However, maintenance respiration is not taken into account in many models despite its importance as a car- bon sink, because it is subtracted from the available assimilate pool at the whole plant level prior to running the partitioning module [24, 25, 27, 77, 75]. Similarly, reserve storage is often ignored or considered a passive, buffering process (except of course in "reserve sinks" such as fruits), although there is some evidence that it may have its own assimilate demand [7]. In relation to the specific definition used in each model, sink strength may be referred to as demand, affinity, capacity; or maximum, potential or conditional growth rate. In some cases it is quantified by two parameters which are analogous to those used in Michaelis-Menten kinetics: one for low-substrate behaviour (equivalent to an affinity) and one for saturating-substrate behaviour (a maximum import rate).

Sink strength can be updated each time step to account for environmental or internal feedback effects. Examples of this flexibility can be found as feedback modulations of the sink demands, by the previously achieved growth $[1,26,63]$, or by the shoot:root imbalance induced by pruning [24]. In the model PEACH [25], growth demand is affected by climatic factors; in VIMO [75] and TREGRO [77], the relevant factor is local nitrogen availability.

Two main subclasses of models can be distinguished in relation to the rules used to derive the actual $\mathrm{C}$ fluxes from sink properties. In the next section, the parameter(s) of the sink strength, regardless of the specific definition used in each model, is referred to as $A_{j}$ for sink \# $j$ (and $B_{j}$ for two-parameter models). $F_{j}$ denotes the actual $\mathrm{C}$ flux allocated by the model to sink $\# j$. The amount of $\mathrm{C}$ available for partitioning is referred to as $P_{N}$ for $\mathrm{C}$ from the whole plant sources, or as $P_{N i}$ for $\mathrm{C}$ from individual branch or leaf source \# $i$.

\subsubsection{Proportional models}

Proportional models were proposed by WarrenWilson [75, 76]. In the basic formulation, the flux allocated to each sink is just proportional to its demand, not exceeding it:

$$
F_{j}=\min \left(\lambda_{j} \cdot P_{N}, A_{j}\right) \quad \text { where } \lambda_{j}=\frac{A_{j}}{\sum_{k} A_{k}} .
$$

However, this formulation does not allow the relative fluxes allocated to different sinks to vary with the global source:sink ratio (see above), so that it has been used in this form in few tree models [24, 63]. Thornley [66] solved the issue with the classical Michaelian formulation. More recently, Escobar-Guttiérrez et al. [18] extended the basic proportional model (Eq. 8) by 


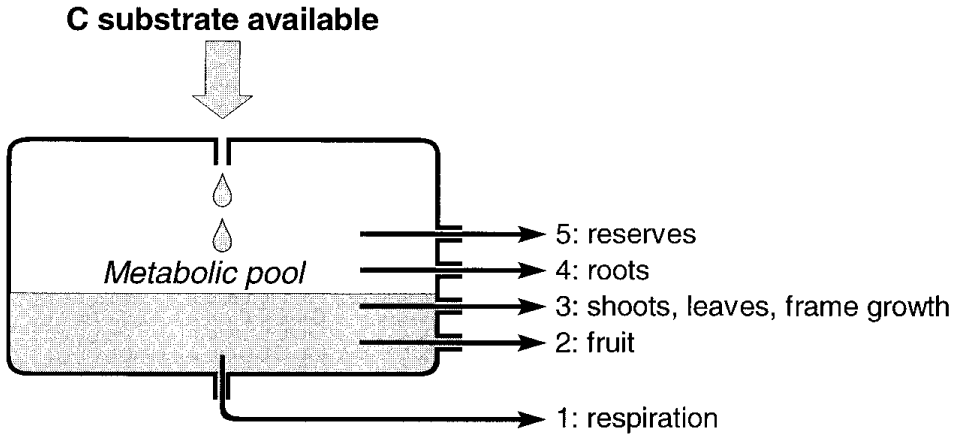

Figure 6. A simple hierarchical model. The total C substrate pool (content of tank) is available only to the sinks with sufficiently high priority levels as numbered right of arrows. Highest priority (1) is at tank bottom level (redrawn after [5]). splitting the sink strength into two components, affinity and maximum import rate:

$$
F_{j}=\min \left(\frac{A_{j}}{\sum_{k} A_{k}} \cdot P_{N}, B_{j}\right)
$$

This formulation was further extended in SIMWAL [1] by taking explicitly into account the effect of source-sink distances, which is implicitly included in the definition of sink strength in the original formulation of proportional models:

$$
F_{j}=\min \left(\sum_{i}\left[\lambda_{i j} \cdot P_{N i}\right], B_{j}\right) \text { where } \lambda_{i j}=\frac{A_{j} \cdot f\left(d_{i j}\right)}{\sum_{k}\left[A_{k} \cdot f\left(d_{i k}\right)\right]}
$$

$f\left(d_{i j}\right)$ being a decreasing function of the distance between source \# $i$ and sink \# $j$.

\subsubsection{Hierarchical models}

In this widespread class of tree models [4, 5, 25-27, $63,77,75]$, sink strength is defined as a maximum growth rate or demand, and the different sinks are ranked according to a priority level order or hierarchy. The sink with highest priority level is supplied first; then, if some assimilates are left after its demand has been met, the sink with priority level \# 2 is supplied, then the sink with priority level \#3, and so on (figure 6). The priority level order is commonly related to the height level within the tree, i.e. roots often have the lowest priority level, as in $[25,63,77]$.

Beside the possible updating of the sink demands and modulation by external factors as mentioned above, flexibility can be introduced in these models by changing the priority levels over time, as in VIMO [75] or by switching out some of the sinks, as in TREGRO [77].

\section{CONCLUSION}

The different models of assimilate partitioning range between two poles, in relation to the main purpose of the model. On one side, the most mechanistic models available, transport resistance models, simulate a simplified version of the basic translocation mechanism, with tree architecture being omitted or very poorly accounted for; on the other side, detailed empirical or architectural models focus on the result of the translocation process as a fine growth pattern of the different plant parts without any reference to the underlying mechanism. Most operational models can be located near the midpoint of those two extremes. Beyond the apparent diversity exhibited in the formulations of the various model classes, the different approaches make a quasi-continuum of concepts, often sharing more common features across classes than could $a$ priori be suspected.

An example of such common concepts is the reference to distance. As reviewed in this paper, the effect of distance on assimilate allocation is a major experimental result which is properly accounted for by the Münch theory. Due to their size, this aspect is more significant in trees than in herbs. It is explicitly included in transportresistance (TR) models where resistance is directly related to pathway length, and also in recent models of other classes like SIMWAL. But it can also be found in an implicit form, as the priority level order of several hierarchical models where the sinks closest to the assimilating leaves are assigned the highest priority level and those farthest away are assigned the lowest priority level. This similarity is manifested in practical consequences: both hierarchical models and TR models are able to simulate the root:shoot ratio in relation to $N$ availability. This can be found in TREGRO (hierarchical) on one hand and in the bi-substrate TR model on the other hand: both achieve this from their own way of accounting for source-sink distances and the further assumption that $N$ allocation is ruled by a process similar to $\mathrm{C}$ allocation. 
As another example, a number of models belonging to a particular class include some elements from another class. In most cases, both model classes are close to each other, e.g. empirical or allometric models often include functional relationships. However, there are also a number of models that mix more different classes, e.g. the model BRANCH which includes both functional relationships and hierarchical rules, or some hierarchical models like PEACH or FAGUS which include a proportional submodel nested within a priority level.

A third, broad example can be mentioned, although the class mixing is implicit and involves partitioning not only among organs but also among functions. In many models of different classes, e.g. PEACH, ECOPHYS or LIGNUM, maintenance respiration $\left(R_{\mathrm{m}}\right)$ is subtracted from the $C$ pool available for partitioning at the whole plant level prior to running the allocation module. This can actually be considered as a hierarchical submodel where $R_{\mathrm{m}}$ is a particular - though delocalized - sink which is assigned the highest priority level. On one hand this may be justified as $R_{\mathrm{m}}$ is indeed vital to any organ; on the other hand this alters the result of the partitioning process compared to the case where $R_{\mathrm{m}}$ is just a component of the carbon demand of each sink, with the possibility to assign $R_{\mathrm{m}}$ the first priority order within each sink after the partitioning process, as in SIMWAL. Delocalizing and prioritizing $R_{\mathrm{m}}$ at the whole plant level prevents some sinks from getting resources in abundance while other sinks would not have enough to survive, which may be considered unlikely in particular situations, e.g. in an homogeneous light environment. However, such an imbalance between favoured and unfavoured sinks, which is enabled in the alternative approach, is likely to occur in more complex situations, e.g. in heterogeneous light environments, illustrating the "branch autonomy" principle [59]. Some forest conifer growth models, e.g. FORDYN or BRANCH, actually include this principle as a branch abscission criterion.

This discussion illustrates the general status of rules in models: while they can be valuable modelling "guard rails" in some particular, usual or "standard" conditions, they may also prevent an efficient simulation of more complex or "non-standard" situations, i.e. situations that do not fall within a "usual" range. A similar conflict arises about the definition and assessment of sink strength, particularly as a maximum import or growth rate. Such a parameter is generally assessed in so-called "non-limiting" conditions, which are actually the upper limit of a particular range of conditions, e.g. when all fruits are removed. However, it is very difficult to know whether this upper limit cannot be exceeded in extreme or uncommon cases, e.g. after severe pruning. Hence, if the model is to account for the flexibility exhibited by "real" trees, particularly in case of environmental accidents, it may be very useful to allow any "maximum" or "potential" values to be updated, e.g. through feedback interactions.

Progress in modelling the sink strength or $\mathrm{C}$ demand can be expected to improve significantly the global efficiency of FSTMs in two particular areas: (i) the dynamics of reserve storage and mobilization, and (ii) the dynamics of radial growth in relation to environmental factors. Both have received little consideration in models so far despite their specific importance in trees as an "integrative memory" in relation to size and perennity. Beside mechanical and hydraulic support (see "functional balance" above), radial growth provides room for reserve storage, and both dynamics are correlated [31, 74]. Regarding $C$ reserve storage, the most relevant issue is whether it is a mere passive buffering process (as generally considered in the few FSTMs that explicitly include reserves) or a more active one, with a specific sink strength associated to it [7]. A similar question arises regarding reserve mobilization as a carbon source, which can be critical when $\mathrm{C}$ demand is intense and no other source is available, e.g. in early spring or after defoliation [2].

Such prospects should improve mostly FSTMs based on source:sink relationships, i.e. mechanistic models. However, the boundaries between the different classes are likely to fade even more in the future with progress in computer performances - for example, architectural models can be expected to include more and more Cbased rules, whereas mechanistic models will describe a more detailed architecture -, so that advances in source:sink models should also benefit other classes of models.

Acknowledgements: Special thanks are due to Drs. C. Coutand, E. Dreyer and B. Moulia for their critical reading and helpful suggestions to improve the manuscript.

\section{REFERENCES}

[1] Balandier P., Lacointe A., Le Roux X., Sinoquet H., Cruiziat P., Le Dizès S., "SIMWAL": a structure - function model simulating single walnut tree growth according to climate and pruning, Ann. For. Sci. 57 (2000) 571-585.

[2] Bamber R.K., Humphreys F.R., Variations in sapwood starch levels in some australian forest species, Aust. For. 29 (1965) 15-23.

[3] Bassow S.L., Ford E.D., Section 8: simple whole tree: TRANS, in: Kiester A.R. (Ed.), NAPAP, Development and use of tree and forest response models (Acidic deposition: state of 
science and technology), Report 17, III, Washington DC, 1990, pp. 83-95.

[4] Bassow S.L., Ford E.D., Kiester A.R., A critique of carbon-based tree growth models, in: Dixon R.K., Meldahl R.S., Ruark G.A., Warren W.G. (Eds.), Process Modelling of forest growth responses to environmental stress, Timber Press, Portland, Oregon, 1990, 50-57.

[5] Baumgärtner J., Wermelinger B., Hugentobler U., Delucchi V., Baronio P., De Bernardinis E., Oertli J.J., Gessler G., Use of a dynamic model on dry matter production and allocation in apple orchard ecosystem research, Acta Hort. 276 (1990) 123-139.

[6] Berninger F., Nikinmaa E., Implications of varying pipe model relationships on Scots Pine growth in different climates, Funct. Ecol. 11 (1997) 146-156.

[7] Cannell M.G.R., Dewar R.C., Carbon allocation in trees: A review of concepts for modelling, in: Begon M., Fitter A.H. (Eds.), Advances in Ecological Research, Vol. 25, Academic Press, London, 1994, pp. 59-104.

[8] Chen J.L., Reynolds J.F., A coordination model of whole-plant carbon allocation in relation to water stress, Ann. Bot. 80 (1997) 45-55.

[9] Coutand C., Étude biomécanique de l'effet d'une flexion contrôlée sur la croissance primaire de la tige de tomate (Lycopersicum esculentum Mill.), Ph.D. Thesis, Université Bordeaux-I, France, 1999, 109 pp.

[10] Davidson R.L., Effect of root/leaf temperature differentials on root/shoot ratios in some pasture grasses and clover, Ann. Bot. 33 (1969) 561-569.

[11] Davis J.T., Sparks D., Assimilation and translocation patterns of carbon-14 in the shoot of fruiting pecan trees, Carya illinoensis Koch, J. Am. Soc. hortic. Sci. 99 (1974) 468-480.

[12] DeJong T.M., Fruit effects on photosynthesis in Prunus persica, Physiol. Plant. 66 (1986) 149-153.

[13] Deleuze C., Houllier F., Prediction of stem profile of Picea abies using a process-based tree growth model, Tree Physiol. 15 (1995) 113-120.

[14] Deleuze C., Houllier F., A transport model for tree ring width, Silva Fenn. 31 (1997) 239-250.

[15] Dewar R.C., A root-shoot partitioning model based on carbon-nitrogen-water interactions and Münch phloem flow, Funct. Ecol. 7 (1993) 356-368.

[16] Dickson R.E., Carbon and nitrogen allocation in trees, Ann. Sci. For. 46 (1989) 631s-647s.

[17] Donnelly J.R., Seasonal changes in photosynthate transport within elongating shoots of Populus grandidentata, Can. J. Bot. 52 (1974) 2547-2559.

[18] Escobar-Gutiérrez A.J., Daudet F.A., Gaudillère J.P., Maillard P., Frossard J.S., Modelling of allocation and balance of carbon in walnut (Juglans regia L.) seedlings during heterotrophy-autotrophy transition, J. Theor. Biol. 194 (1998) 29-49.

[19] Farquhar G.D., Caemmerer (von) S., Berry J.A., A biochemical model of photosynthetic $\mathrm{CO}_{2}$ assimilation in leaves of $\mathrm{C}_{3}$ species, Planta 149 (1980) 78-90.
[20] Farrar J.F., Sink strength: What is it and how do we measure it? Forum, Plant Cell Environ. 16 (1993) 1013-1046.

[21] Ford R., Ford E.D., Structure and basic equations of a stimulator for branch growth in the Pinaceae, J. Theor. Biol. 146 (1990) 1-13.

[22] Ford E.D., Avery A., Ford R., Simulation of branch growth in the Pinaceae: Interactions of morphology, phenology, foliage productivity, and the requirement for structural support, on the export of Carbon, J. Theor. Biol. 146 (1990) 15-36.

[23] Fournier M., Bailleres H., Chanson B., Tree biomechanics: growth, cumulative prestresses, and reorientations, Biomimetics 2 (1994) 229-251.

[24] Génard M., Pagès L., Kervella J., A carbon balance model of peach tree growth and development for studying the pruning response, Tree Physiol. 18 (1998) 351-362.

[25] Grossman Y.L., DeJong T.M., PEACH: A simulation model of reproductive and vegetative growth in peach trees, Tree Physiol. 14 (1994) 329-345.

[26] Harpaz A., Gal S., Goldschmidt E.E., Rabber D., Gelb E., A model of the annual cycle of dry matter production and partition in citrus and other evergreen fruit trees, Acta Hortic. 276 (1990) 149-155.

[27] Hoffmann F., FAGUS, a model for growth and development of beech, Ecol. Modell. 83 (1995) 327-348.

[28] Host G.E., Isebrands J.G., Theseira G.W., Kiniry J.R., Graham R.L., Temporal and spatial scaling from individual trees to plantations: a modeling strategy, Biomass and Bioenergy 11 (1996) 233-243.

[29] Kellomäki S., Strandman H., A model for the structural growth of young Scots pine crowns based on light interception by shoots, Ecol. Modelling 80 (1995) 237-250.

[30] Kozlowski T.T., Keller T., Food relations of woody plants, Bot. Rev. 32 (1966) 293-382.

[31] Lacointe A., Kajji A., Daudet F.A., Archer P., Frossard J.S., Mobilization of carbon reserves in young walnut trees, Acta bot. Gallica 140 (1993) 435-441.

[32] Luan J., Muetzelfeldt R.I., Grace J., Hierarchical approach to forest ecosystem simulation, Ecol. Modell. 86 (1996) 37-50.

[33] Maillard P., Deléens E., Castell F., Daudet F.A., Source-sink relationships for carbon and nitrogen during early growth of Juglans regia L. seedlings: analysis at two elevated $\mathrm{CO}_{2}$ concentrations, Ann. For. Sci. 56 (1999) 59-69.

[34] Mäkelä A., Implications of the pipe-model theory on dry matter partitioning and height growth in trees, J. Theor. Biol. 123 (1986) 103-120.

[35] Mäkelä A., Modelling structural functional relationships in whole-tree growth resource allocation, in: Dixon R.K., Meldahl R.S., Ruark G.A., Warren W.G. (Eds.), Process Modelling of forest growth responses to environmental stress, Timber Press, Portland, Oregon, 1990, pp. 81-95.

[36] Mäkelä A., A carbon balance model of growth and self-pruning in trees based on structural relationships, For. Sci. 43 (1997) 7-23. 
[37] Mäkelä A., Hari P., Stand growth model based on carbon uptake and allocation in individual trees, Ecol. Modell. 33 (1986) 204-229.

[38] Mäkelä A., Sievänen R., Comparison of two shoot-root partitioning models with respect to substrate utilization and functional balance, Ann. Bot. 59 (1987) 129-140.

[39] Mäkelä A., Sievänen R., Height growth strategies in open-grown trees, J. Theor. Biol. 159 (1992) 443-467.

[40] Mäkelä A., Vanninen P., Ikonen V.P., An application of process-based modelling to the development branchiness in Scots pine, Silva Fenn. 31 (1997) 369-380.

[41] Mattheck C., Biomechanical optimum in woody stems, in: Gatner B.L. (Ed.), Plant stems, Academic Press, New York, 1995, pp. 75-90.

[42] Mattheck C., Teschner M., Schäfer J., Mechanical control of root growth: a computer simulation, J. Theor. Biol. 184 (1997) 261-269.

[43] McMahon T.A., Kronauer R.E., Tree structures: deducing the principle of mechanical design, J. Theor. Biol. 59 (1976) 443-466.

[44] McMurtrie R., Wolf L., Above- and below-ground growth of forest stands: a carbon budget model, Ann. Bot. 52 (1983) 437-448.

[45] Minchin P.E.H., Thorpe M.R., Farrar J.F., A simple mechanistic model of phloem transport which explains sink priority, J. Exp. Bot. 44 (1993) 947-955.

[46] Moulia B., Fournier M., Optimal mechanical design of plant stems: the models behind the allometric power laws, in: Jeronimidis G., Vincent J.F.V. (Eds.), Plant Biomechanics, Centre for Biomimetics, Univ. of Reading, Reading (UK), 1997, pp. 43-55.

[47] Münch E., Die Stoffbewegungen in der Pflanze, Gustav Fischer, Jena, 1930.

[48] Perttunen J., Sievänen R., Nikinmaa E., Salminen H., Saarenmaa H., Väkevä J., LIGNUM: A Tree Model Based on Simple Structural Units, Ann. Bot. 77 (1996) 87-98.

[49] Priestley C.A., Catlin P.B., Short-term responses to supplementary nitrogen in young apple trees as related to carbohydrate nutrition, Ann. Bot. 38 (1974) 469-476.

[50] Promnitz L.C., A photosynthate allocation model for tree growth, Photosynthetica 9 (1975) 1-15.

[51] Rauscher H.M., Isebrands J.G., Host G.E., Dickson R.E., Dickmann D.I., Crow T.R., Michael D.A., ECOPHYS: An ecophysiological growth process model for juvenile poplar, Tree Physiol. 7 (1990) 255-281.

[52] Reffye (de) Ph., Fourcaud T., Blaise F., Barthélémy D., Houllier F., A functional model of tree growth and tree architecture, Silva Fenn. 31 (1997) 297-311.

[53] Reffye (de) Ph., Houllier F., Blaise F., Fourcaud T., Essai sur les relations entre l'architecture d'un arbre et la grosseur de ses axes végétatifs, in: Bouchon J, Reffye (de) Ph., Barthélémy D. (Eds.), Modélisation et simulation de l'architecture des végétaux, INRA Éditions, Paris, 1997, pp. 255-423.

[54] Reynolds J.F., Chen J.L., Modelling whole-plant allocation in relation to carbon and nitrogen supply. Coordination versus optimization: Opinion, Plant Soil 185 (1997) 65-74.
[55] Reynolds J.F., Thornley J.H.M., A shoot-root partitioning model, Ann. Bot. 49 (1982) 587-597.

[56] Sheehy J.E., Mitchell P.L., Durand J.L., Gastal F., Woodward F.I., Calculation of translocation coefficients from phloem anatomy for use in crop models, Ann. Bot. 76 (1995) 263-269.

[57] Shinozaki K., Yoda K., Hozumi K., Kira T., A quantitative analysis of plant form: the Pipe model theory. I. Basic analyses, Jpn. J. Ecology 14 (1964) 97-105.

[58] Sorrensen-Cothern K.A., Ford E.D., Sprugel D.G., A model of competition incorporating plasticity through modular foliage and crown development, Ecol. Monogr. 63 (1993) 227304.

[59] Sprugel D.G., Hinckley T.M., Schaap W., The theory and practice of branch autonomy, Ann. Rev. Ecol. Syst. 22 (1991) 309-334.

[60] Stokes A., Nicoll B.C., Coutts M.P., Fitter A.H., Response of young Sitka spruce clones to mechanical pertutbation and nutrition: effects on biomass allocation, root development, and resistance to bending, Can. J. For. Res. 27 (1997) 1049-1057.

[61] Takenaka A., A simulation model of tree architecture development based on growth response to local light environment, J. Plant Res. 107 (1994) 321-330.

[62] Telewski F.W., Gardiner B.A., White G., PlovanovichJones A., Wind flow around multi-storey buildings and its influence on tree growth, in: Jeronimidis G., Vincent J.F.V. (Eds.), Plant Biomechanics, Centre for Biomimetics, Univ of Reading, Reading (UK), 1997, pp. 179-183.

[63] Thaler P., Pagès L., Modelling the influence of assimilate availability on root growth and architecture, Plant soil 201 (1998) 307-320.

[64] Thornley J.H.M., A model to describe the partitioning of photosynthates during vegetative plant growth, Ann. Bot. 36 (1972) 419-430.

[65] Thornley J.H.M., A balanced quantitative model for root:shoot ratios in vegetative plants, Ann. Bot. 36 (1972) 431441.

[66] Thornley J.H.M., Root:shoot interactions, in: Integration of activity in the higher plant, Jennings D.H. (Ed.), Symposium of the Society for Experimental Biology, Cambridge University Press, London, 1977, pp. 367-389.

[67] Thornley J.H.M., A transport-resistance model of forest growth and partitioning, Ann. Bot. 68 (1991) 211-226.

[68] Thornley J.H.M., Shoot:Root allocation with respect to $\mathrm{C}, \mathrm{N}$ and $\mathrm{P}$ : an investigation and comparison of resistance and teleonomic models, Ann. Bot. 75 (1995) 391-405.

[69] Thornley J.H.M., Modelling allocation with transport/conversion processes, Silva Fenn. 21 (1997) 341-355.

[70] Valentine H.T., Tree Growth Models: Derivations employing the Pipe Model Theory, J. Theor. Biol. 117 (1985) 579-585.

[71] Valentine H.T., A carbon balance model of stand growth: a derivation employing pipe-model theory and the selfthinning rule, Ann. Bot. 62 (1988) 389-396. 
[72] Valentine H.T., Height growth, site index, and carbon metabolism, Silva Fenn. 31 (1997) 251-263.

[73] Wardlaw I.F., The control of carbon partitioning in plants, New Phytol. 116 (1990) 341-381.

[74] Wargo P.M., Starch storage and radial growth in woody roots of sugar maple, Can. J. For. Res. 9 (1979) 49-56.

[75] Warren-Wilson J., Ecological data on dry matter production by plants and plant communities, in: Bradley E.F., Denmead O.T. (Eds.), The collection and processing of field data, Interscience Publishers, New York, 1967, pp. 77-123.

[76] Warren-Wilson J., Control of crop processes, in: Rees A.R., Cockshull K.E., Hand D.W., Hurd R.G. (Eds.), Crop processes in controlled environment, Academic Press, New York, 1972, pp. 7-30.
[77] Weinstein D.A., Beloin R.M., Yanai R.D., Modeling changes in red spruce carbon balance and allocation in response to interacting ozone and nutrient stresses, Tree Physiol. 9 (1991) 127-146.

[75] Wermelinger B., Baumgärtner J., Guttierrez A.P., A demographic model of assimilation and allocation of carbon and nitrogen in grapevines, Ecol. Modell. 53 (1991) 1-26.

[76] West P.W., Model of above-ground assimilate partitioning and growth of individual trees in even aged forest monoculture, J. Theor. Biol. 161 (1993) 369-394.

[77] Wilson J.B., A review of evidence on the control of shoot:root ratio in relation to models, Ann. Bot. 61 (1988) 433449.

[78] Zhang Y., Reed D.D., Cattelino P.J., Gale M., Jones E.A., Liechty H.O., Mroz G.D., A process-based growth model for young red pine, For. Ecol. Manag. 69 (1994) 21-40. 